\title{
Application and Analysis of STATCOM in Hub Substation
}

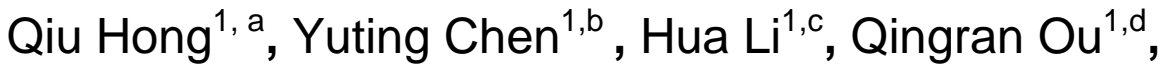 \\ Shilan Shen ${ }^{1, e}$ and Hongwei Zhang ${ }^{1, f}$ \\ ${ }^{1}$ Guangzhou Power Supply Bureau, Guangzhou Guangdong, China \\ ahongqiu1983@126.com, bxiaoting0401@sina.com, gzpsc@126.com, \\ douqr@guangzhou.csg.cn,"343297505@qq.com,454837134@qq.com
}

\begin{abstract}
Keywords: STATCOM, voltage regulation, power quality, power grid operation
Abstract. With the development of power electronics technology and popularization, STATCOM has been widely used in power system. Its smooth voltage regulation curve and precise adjustment ability, greatly improved the power quality of the power system. This paper takes the STATCOM project of China Southern Grid Corp 500kV substation as an example, analyzed the operation mode and voltage regulation principle, and through the actual operation of the situation, illustrates the importance and advantages of STATCOM in the operation of power grid.
\end{abstract}

\section{Introduction}

Power system use a conventional three-phase power transmission mode to transmit power, in recent years, HVDC technology is becoming more and more mature. Due to the rapid development of economy in Pearl River Delta region, the demand of electricity is booming, however, there is insufficient power supply capacity in this region. China has abundant hydro, coal resources in the western region, when the local government use hydroelectric power and pit-head power plant to generate electricity, there is a great surplus. By transmitting the electricity from the western areas to East China, the lack of electricity has be gradually solved [1]. As Tian-Guang, Chu-Sui and Niu-Cong DC power transmission system were put into operation, China Southern Power Grid has formed a "8AC and 9DC" high voltage transmission network, that presents the characteristics of "stronger DC and weaker AC", and the interaction between $\mathrm{AC}$ and $\mathrm{DC}$ is prominent. When 500kV Beijiao Substation suffer single-phase or three-phase short circuit fault, it will result in DC commutation failure of the eight DC transmission lines. If the AC system fault cannot be removed quickly, then the continued DC commutation failure may lead to DC blocking, and the system may lose stability.

\section{Principle of STATCOM}

STATCOM make the Inverter circuit parallel connected to the electricity grid directly or through reactor. It can adjust the phase and amplitude of the output ac voltage of the bridge type circuit, or direct control the output AC current, to make the circuit generate or absorb reactive current which required. Then STATCOM can achieve the purpose of dynamic reactive power compensation.

Set the grid voltage and the output AC voltage of STATCOM expressed in phasor $U_{S}$ and $U_{I}^{\&}$, then the voltage $\left(U_{\mathrm{L}}\right)$ on the connection reactance $\mathrm{X}$ is the phase difference between $U_{\mathrm{S}}$ and $U_{\mathrm{I}}$, and the current of the connection reactance can be controlled by its voltage. The current (I) is what STATCOM absorbed from the grid [2-3]. Without the loss of the connection reactance and the inverter, the equivalent circuit and working principle of STATCOM is shown in figure 1. In this case,

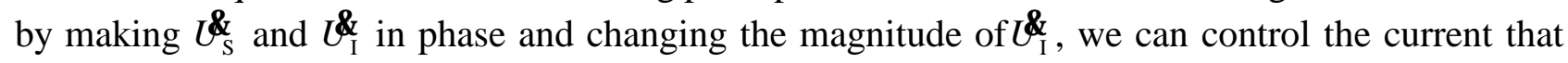
STATCOM absorb from the grid advanced or lag $90^{\circ}$, and can control the size of the current. 

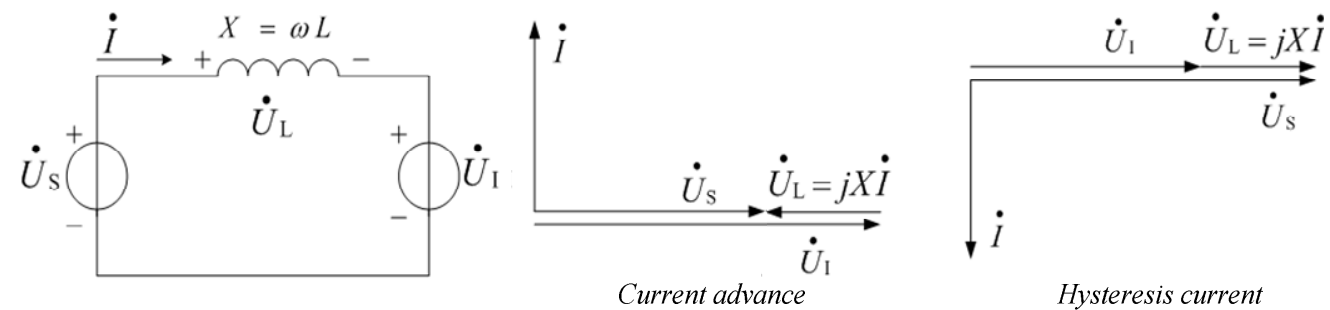

Fig. 1 The equivalent circuit and working principle of STATCOM

\section{Circuit Topology of STATCOM}

There are two sets of STATCOM in Beijiao Substation, the capacity size of one set of STATCOM is \pm 100 Mvar, and the voltage level is $35 \mathrm{kV}$. The system access method of the STATCOM is shown in figure 2.

STATCOM is delta connection, accessed to $35 \mathrm{kV}$ busbar through series reactor and circuit breaker. $35 \mathrm{kV}$ systems is connected with $220 \mathrm{kV}$ busbar through special transformer. During normal operation, STATCOM adjusts the voltage level of busbar together with capacitor and reactor. Once the system suffer the ground fault, STATCOM can instantaneously provide output that 1.5 times the rated power, so it can provide reactive support for the system, and then ensure the stability of bulk power system.

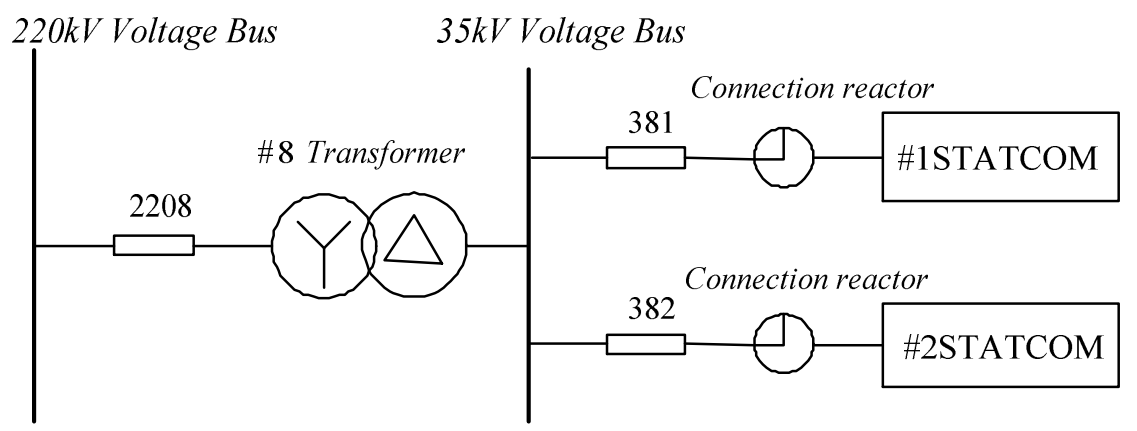

Fig. 2 The System access method Of the STATCOM

STATCOM uses a cascading way to connect, the structure of single-phase converter chain is shown in figure 3.

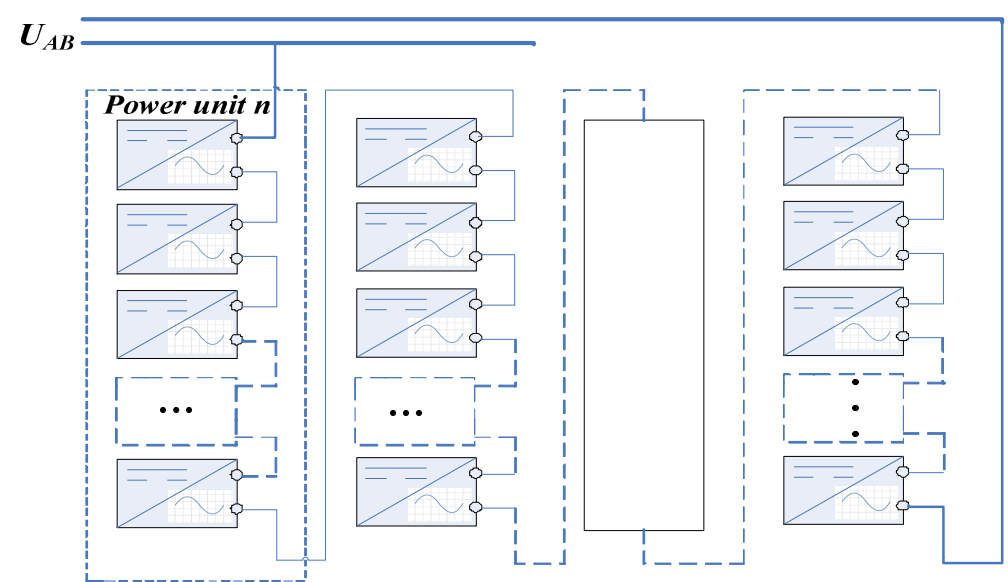

Fig. 3 The composition of single phase flow chain

Single-phase converter chain consists of 27 converter unit, and the topology of the converter unit is back-to-back H-bridge, it charging energy-storage capacitor through the PWM rectifier circuit. By controlling on-off mode of the system drives switching element (IGBT), converter chain providing an output. 


\section{Control Strategy}

The main function of STATCOM of Beijiao station is to improve the transient voltage stability, prevent voltage collapse; and provide dynamic reactive power support, accelerating voltage recovery after fault, under the control of scheduling, can participate in the station's reactive power capacity to participate in the daily operation of the steady-state voltage regulation.

Control mode

According to the operation characteristics of Guangzhou power grid, the control mode of STATCOM has the following five modes:

1) Artificial intervention mode

2) Transient voltage control mode

3) Remote control mode

4) Steady-state voltage regulation mode

5) Steady state reactive power control mode

In the field application, STATCOM always operation in the steady-state voltage regulation mode, according to the system's voltage change and automatic regulation, the target voltage of the STATCOM is the $220 \mathrm{kV}$ bus voltage. In order to ensure that the device has enough dynamic reactive power reserve, the output capacity of the STATCOM is selected as follows: the upper limit of the capacity is slightly less than that of a group of capacitors, the inductive limit is slightly less than a group of reactors, and the value is $40 \mathrm{Mvar}$.

In the transient mode, when the effective value of the three-phase voltage is lower than the blocking voltage threshold of $80.3 \mathrm{kV}$ (0.4p.u.), STATCOM control system judged that the occurrence of short circuit faults. In order to avoid the device to enter the transient mode and increase system short circuit current, the transient control mode closed lock voltage control, at the same time to start the zero reactive power control, the output of the device is zero, until the zero reactive power control exit. The logic of its transient control mode is shown in Figure 4:

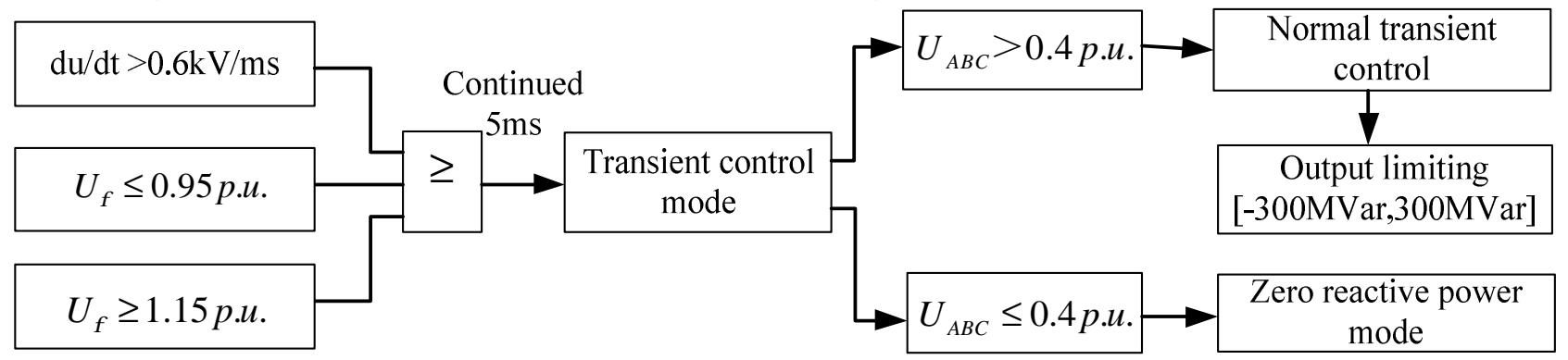

Fig. 4 Logic of STATCOM in the transient control mode

When the STATCOM is in the transient control mode and does not meet the conditions of zero reactive power, the STATCOM voltage regulator combines the nonlinear gain function, and the gain optimization is started, contribute to the realization of the full power of reactive power as soon as possible, after entering the transient state issued 1.5 times the rated capacity of reactive power [4].

Output mode

STATCOM can be divided into two kinds of operation mode: equal capacity operation mode and unequal capacity operation mode.

1) Equal capacity operation mode

Each valve output reactive power calculation for half of the reactive power compensation, reactive power valve output equal to two sets of STATCOM, The output value of the reactive power is calculated by the reference current, and the pulse signal is transmitted to the device level controller

2) Unequal capacity operation mode

Prior to the two sets of valve group to carry out the main and sub distribution. When the target is less than 100Mar, the STATCOM main valve set to adjust the output of a given reactive power, sub 
valve group output zero. When the target compensates for the reactive power is greater than 100Mvar, STATCOM main valve group output $100 \mathrm{Mvar}$, the remaining part is output by the side valve group.

The STATCOM of Beijiao station in peacetime participate in the regulating reactive power and the Limit of reactive power is $40 \mathrm{Mvar}$, the equal capacity mode of adopted.

\section{STATCOM operation}

The control system can identify the fault by the magnitude and change speed of the effective value of the three-phase voltage. And according to the severity of the fault to achieve the corresponding control strategy. When a fault occurs in a large power grid, STATCOM detect system voltage fluctuation, and then enter the transient mode [5].

A case study of Single phase earth fault of $500 \mathrm{kV}$ bus in $500 \mathrm{kV}$ Huadu substation, Beijiao station and Huadu station were connected by $500 \mathrm{kV}$ double circuit, STATCOM in Beijiao station detected abnormal, and enter transient mode. The $220 \mathrm{kV}$ bus voltage waveform at fault is shown in Fig.5, and the output current waveform of STATCOM at fault is shown in Fig.6.

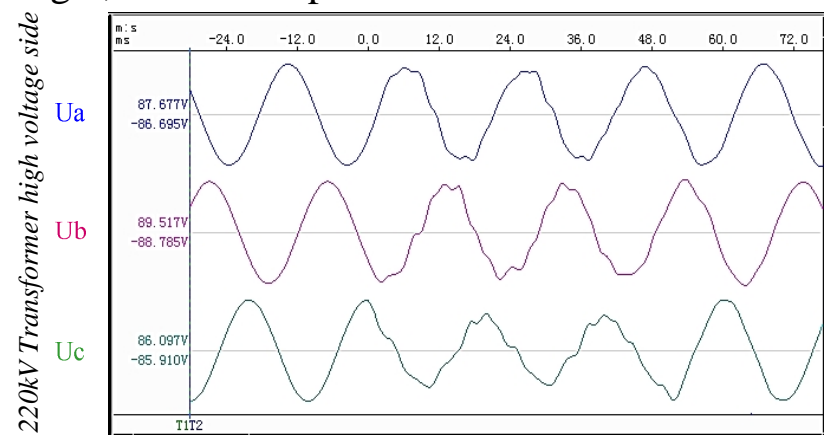

Fig5: the voltage waves of $220 \mathrm{kV}$ Bus at fault

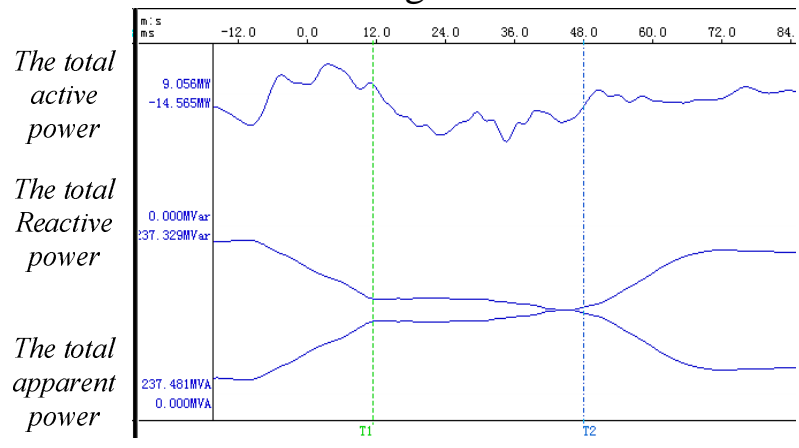

Fig6: the current waves of STATCOM at fault

Through the analysis, STATCOM in the actual operation, can accurately detect the system's fault, and enter the transient mode, the dynamic response time is about $9 \mathrm{~ms}$, the response is rapid, and the reactive power is $237.48 \mathrm{Mvar}$. It supplements the reactive power of the large system.

\section{Conclusions}

The application of STATCOM in 500kV Beijiao station, it has greatly guaranteed the stability of the large system of the southern power grid.

Application of STATCOM in Beijiao station, it has greatly guaranteed the stability of the large system of the southern power grid. In the operation of STATCOM, the control mode and operation experience are discussed, and the analysis of the status of the power grid fault, STATCOM response quickly, to provide reactive power support system. This paper has done some research on the application of STATCOM in power grid.

\section{References}

[1] Di Yajing, Research for the device of multiple objective control in voltage quality[J]. Aotumation Of Electric Power Systems. 2009,33(12):80-84.

[2] Lee T L, Hu S H. D-STATCOM with positive-sequence admittance and negative-sequence conductance to mitigate voltage fluctuations in high-level penetration of distributed generation systems[J]. IEEE Transactions on Industrial Electronics，2013，60(4): 1417-1428.

[3] Lu Xing, Hong Qiu, Zhang WenYuan, Research on device of multilevel voltage quality adjustment based on FPGA control[J]. Power System Technology. 2012,36(5):150-155 
[4] Li Chunhua, Huang Weixiong, Yuan Zhichang ,Systematic Control Strategies for \pm 200 Mvar Cascaded STATCOM in China Southern Power Grid, Automation of Electric Power Systems, 2013,37(3):116-121

[5] Mei Yongzhen, Wang Haiyuan, Influence of STATCOM on Power Quality of Transmission System and Receiving-End [J], Power System and Clean Energy, 2016,32(8):1-6. 